\title{
Entumecimiento higrométrico del hormigón
}

MANUEL FERNANDEZ CANOVAS

Dr. Ing. de Construcción

I.E.T.c.c.

\section{INTRODUCCION}

Las deformaciones termo-higrométricas del hormigón durante el proceso de endurecimiento han llamado la atención de muchos y notables investigadores en las últimas décadas. Son muchos los trabajos que se encuentran en los archivos bibliográficos que tratan de este tema y algunas las monografías que profundizan en las teorías de las deformaciones higrométricas. Sin embargo, se observa que el interés del investigador ha estado siempre centrado en el fenómeno de la retracción, es decir, la disminución volumétrica o lineal, en su caso, del hormigón como consecuencia de un proceso de pérdida de agua.

Es fácil comprender el por qué la inquietud se ha centrado hacia el fenómeno de retracción si tenemos en cuenta que ha sido la causa de todo un cuadro patológico del hormigón. La débil capacidad resistente del hormigón, frente a tensiones de tracción, ha sido motivo de fisuración siempre que se han producido retracciones de origen térmico o hidráulico y estas tensiones, provocadas por dichos efectos, han superado la resistencia a tracción del hormigón.

Las características de estas fisuras, su localización, trayectoria, evolución, amplitud, etc., etc., han permitido a simple vista observar las consecuencias del fenómeno tensional y tener idea de la importancia que en los diversos puntos podía tener la retracción. Pero ¿qué motivaba esta retracción? ¿qué agua se perdía? ¿Cómo se eliminaba ésta? Todas estas preguntas dieron lugar a estudios profundos en los cuales se analizaba la influencia de los cementos, áridos, aditivos, relación agua:cemento, humedad relativa, temperatura, etcétera.

Se ha comprobado que en la retracción pueden influir tres tipos de agua: el agua libre, con poca o ninguna influencia en las variaciones dimensionales; el agua ligada físicamente, que es la más importante desde el punto de vista de cambios dimensionales, y el agua combinada, que sólo interviene cuando existen condiciones excepcionales de duración y temperatura.

La porosidad, capilaridad, adsorción, imbibición, etc., tienen una gran influencia en las variaciones dimensionales del hormigón.

Analizando las publicaciones existentes puede decirse que el fenómeno de la retracción está bastante bien definido y conocido, llegándose incluso mediante teorías físicas a plan- 
tearse una serie de ecuaciones diferenciales cuyas soluciones explican muy bien el proceso y permiten obtener valores que están muy próximos a los reales.

Hay otro tipo de deformación higrométrica que tiene diferente signo al de retracción y que da lugar por tanto a un aumento de volumen, es decir, a un entumecimiento. Este fenómeno ocurre en hormigones que están en contacto con agua y es debido a un proceso totalmente físico o físico-químico, a diferencia de los aumentos de volumen o expansiones que tienen su origen en fenómenos puramente químicos y que también ocurre en presencia de agua, como ocurre a las expansiones producidas por la cal libre de los cementos, por el óxido de magnesio fundamentalmente cristalino, por las reacciones de los álcalis del cemento con determinados áridos silícicos e, incluso, los debidos a la acción de los cloruros o sulfatos sobre los aluminatos del cemento.

El entumecimiento a que nos referimos tiene lugar cuando un hormigón que se ha secado al aire con una humedad relativa baja se coloca en contacto con el agua o se sitúa en un ambiente de más alta humedad, o bien, cuardo un hormigón está desde sus primeros días en contacto con el agua.

El fenómeno del entumecimiento ha sido poco estudiado y únicamente algunos especialistas en hormigón lo mencionan, un tanto de pasada, al estudiar la retracción. Sin embargo, hemos visto que este cambio dimensional, aunque no es tan espectacular como el de retracción, por los efectos que produce, puede ser también causa de efectos patológicos tan importantes como los ocasionados por la retracción. Es verdad que las expansiones van a dar origen, por lo general, a compresiones y, ante estas acciones, el hormigón está bien preparado por su elevada resistencia a compresión. Al ser pequeño el peligro de fisuración poca importancia puede parecer que teriga el entumecimiento, sin embargo, sí lo tiene por cuanto indirectamente puede dar lugar a fisuraciones y directamente a otros muchos efectos entre los cuales merecen destacarse las deformaciones diferenciales en paredes de hormigón sometidas por una cara a la acción del agua y por la otra a la del aire seco. Estos efectos son típ:cos de depósitos de agua y presas de hormigón.

El motivo de haber realizado este estudio rad:có precisamente en los problemas que se presentaron en una presa en la que, por razones técnicas, durante varios años no pudo embalsarse agua. El hormigón de la presa, por estas causas, estuvo sometido a acciones climáticas muy variables, pero en las que predominaban las altas temperaturas en verano y humedades relativas bajas, con lo cual el hormigón sufrió un proceso activo de retracción.

Al fin, se realizó el embalse de agua hasta su cota máxima y a partir de entonces se empezó a observar un ligero movimiento de uno de los bloques de coronación, precisamente en el que por estar situado en la zona de compuertas tenía una dosificación más alta de cemento y el hormigón era de mejor calidad.

Después de estudiar y descartar todas las posibles causas, tanto técnicas como mecánicas de estabilidad, o químicas que pudiesen haber sido producidas por algún agente agresivo, llegamos a la conclusión de que el fenómeno podía responder a una deformación higrométrica producida por la imbibición de agua en la cara aguas arriba del hormigón, mientras que la del paramento aguas abajo seguía bajo los efectos externos de sequedad. Al ser el hormigón de este bloque de características diferentes a los demás se explicaba que los sntumecimientos fuesen d:ferentes, con lo que en definitiva existía un movimiento relativo de éste con respecto a los adyacentes dando la sensación de un desplazamiento, cuando en realidad se trataba de un curvado del mismo. 
Este fenómeno realmente importante y sin antecedentes hizo que prestásemos atención al entumecimiento y que hiciésemos algunos ensayos para ver cómo se comportaban diferentes tipos de hormigón en contacto con el agua.

\section{ANALISIS DEL ENTUMECIMIENTO}

Cuando un mortero u hormigón conservado en agua o en cámara húmeda se lleva a una atmósfera seca, se ha comprobado que experimenta una retracción acompañada de una pérdida de peso debida al agua que elimina por evaporación. Si de nuevo el mortero u hormigón se lleva al agua, se observa cómo este material se entumece y recupera el peso por imbibición de agua.

También la experimentación ha demostrado que las leyes que ligan estos movimientos con las variaciones de agua son diferentes según la cantidad de árido que exista en el material y la edad que éste tenga; así, se ha visto que, cuando se trata de pastas de cemento de bastante edad, existe una relación prácticamente lineal entre movimiento y variación de agua; ésta es curvilínea para pastas jóvenes, y los movimientos se hacen menos sensibles a las variaciones de agua para hormigones con alto contenido de áridos.

También se ha observado, mediante la realización de ciclos de desecación y humectación, la existencia de una determinada inercia que da lugar a la aparición de una histéresis, de tal forma que para valores idénticos en el contenido de agua, el valor de la retracción es superior durante el ciclo de humectación al que se presenta durante el de desecación, es decir, no existe recuperación total dándose lugar por tanto a la aparición de histéresis.

La retracción residual que se pone de manifiesto en los ciclos repetidos de desecaciónhumectación, puede ser variable de acuerdo con la naturaleza del hormigón y la importancia del contenido en agua.

En estos movimientos, en los que se producen efectos de acomodación compensados por efectos de fatiga, intervienen: el agua libre, cuyo volumen depende de los huecos existentes en la pasta o en el hormigón y que no influye o lo hace muy poco en las variaciones dimensionales, y el agua ligada físicamente, que interviene como causa principal de estas variaciones.

A temperaturas superiores a $200^{\circ} \mathrm{C}$, el fenómeno de retracción se agudiza como consecuencia de pérdida de agua combinada que sólo puede eliminarse en condiciones excepcionales de duración y temperatura.

Así como la retracción está condicionada en su mayor parte a un fenómeno de evaporación, el entumecimiento lo está a uno de absorción y de adsorción.

Es difícil definir la ley de ganancia de agua por absorción y por adsorción en función del tiempo; de todas formas, lo que sí está claro es que desde el momento en que la superficie de un hormigón seco queda en contacto con el agua se produce una migración de ésta hacia el interior del mismo y la velocidad de difusión de este agua va a depender mucho del estado de sequedad del hormigón y del diámetro de los conductos que presente su red capilar. Esta fase tiene mucha importancia en piezas de gran masa, en las que la cantidad de agua libre en los poros as muy escasa en relación con la que humedece las superficies.

El fenómeno de adsorción es más complejo y está ligado no sólo a la finura de molido de los cementos, sino también a la presencia de posibles adiciones a los mismos e, incluso, a 
la naturaleza mineralógica de ambos. En realidad se trata de un fenómeno de imbibición de agua por geles y su influencia en el ertumecimiento de los hormigones es importante.

Ambos fenómenos, absorción y adsorción, tienen lugar al principio con bastante velocidad, si bien los procesos se van haciendo cada vez más lentos conforme se va llegando a la saturación.

La influencia que pueden tener los diferentes componentes de los hormigones en el entumecimiento queda puesta de manifiesto en las experiencias de Dutron que muestra cómo para diferentes cementos, éste crece en el siguiente orden: puzolánico, portland, portland altas resistencias iniciales y aluminoso, produciéndose además variaciones dentro de cada tipo de cemento de acuerdo con su categoría y clase en el sentido de que a mayor finura de molido se obtiene mayor entumecimiento.

Algunos aditivos añadidos al hormigón pueden producir modificaciones y así, por ejemplo, la adición de $\mathrm{Cl}_{2} \mathrm{Ca}$, aumenta el entumecimiento.

La naturaleza mineralógica de los áridos también influye en el entumecimiento, al igual que lo hace en la retracción, dando valores mayores para áridos calizos y menores para los de naturaleza silícea.

La relación agua/cemento tiene también influencia, aunque en menor proporción de lo que cabría esperarse, pues fundamentalmente sus efectos se aprecian por la cantidad de capilares a que dé lugar y no por la cantidad de huecos. En este sentido puede observarse que hormigones con relaciones agua/cemento medias pueden dar lugar a entumecimientos superiores a los de relaciones más altas, debido a que en aquéllos la presencia de capilares es superior a los últimos en los que los huecos son mayores y con efectos menos notables en los fenómenos de absorción.

Cuando un cemento se amasa y la pasta se conserva en agua, se puede observar que ésta experimenta un aumento de volumen decreciente con el tiempo. Para una pasta de cemento portland se han obtenido alargamientos de $13 \times 10^{-4} \mathrm{~m} / \mathrm{m}$ a 100 días, de $20 \times 10^{-4}$ $\mathrm{m} / \mathrm{m}$ a 1.000 días y $22 \times 10^{-4} \mathrm{~m} / \mathrm{m}$ a 2.000 días.

Dutron observó en sus investigaciones que ei aumento de longitud experimentado por las pastas es muy variable y que el entumecimiento va acompañado de una ganancia en peso, pero que este aumento de volumen era inferior al que correspondía a la ganancia en peso de agua. lo que demostraba que había una contracción en la combinación líquido-sólido simultánea con el aumento de volumen aparente.

El entumecimiento de los hormigones en agua es inferior que el experimentado por las pastas de cemento puras. Así, para un hormigón de $300 \mathrm{~kg} / \mathrm{m}^{3}$ de cemento, el entumecimiento lineal es de 1 a $1,5 \times 10^{-1} \mathrm{~m} / \mathrm{m}$ a 1.000 días, con un aumento de peso del 1 por 100 .

Los morteros conservados en agua desde su amasado presentan entumecimientos de 1,5 a $3 \times 10^{-1} \mathrm{~m} / \mathrm{m}$ a 275 días para una dosificación de cemento de $500 \mathrm{~kg} / \mathrm{m}^{3}$, dependiendo del tipo de cemento, siendo de $3 \times 10^{-1}$ para el cemento aluminoso; $2,4 \times 10^{-1}$ para el portland ARI; $2,3 \times 10^{-1}$ para el portland y $1,6 \times 10^{-4}$ para el cemento puzolánico.

La ley de entumecimientos en función del tiempo es de tipo logarítmico, obedeciendo a una ecuación de la forma $E=k \log t$, en la que $E$ es el entumecimiento lineal, $k$ es una constante y $t$ es el tiempo. Los valores de $k$ dependen del tipo de cemento, granulometría, 
tamaño máximo de árido, dosificación de cemento, etc. De todas formas mediante ensayos se ha podido comprobar que para pastas y hormigones sumergidos en agua después de amasados prácticamente se logra la estabilización a los seis años para las pastas y al año para los hormigones.

Hasta aquí hemos supuesto que la pasta, mortero u hormigón no habían cambiado de ambiente y su conservación había sido siempre en atmósfera saturada de agua. Si el hormigón ha sufrido una desecación al aire y se le sitúa en contacto con agua o en un ambiente de mayor humedad relativa, éste experimenta también un entumecimiento; pero hay que tener en cuenta que durante el tiempo que el material estuvo en ambiente seco sufrió una retracción de secado más o menos importante dependiendo de la humedad relativa y de la duración de su exposición a aquel ambiente. Cuando el hormigón en estas condiciones se pone en contacto con el agua empieza a entumecer, pero la retracción de secado no se compensa, es decir, no llega a desaparecer del todo, aun cuando el tiempo durante el cual esté en contacto con el agua sea muy grande. Como consecuencia de esto queda una retracción residual o irreversible, cuyo valor suele oscilar entre 0,3 y 0,5 , siendo normal el de 0,3 .

La irreversibilidad del fenómeno parece ser debida a la aparición de enlaces adicionales en los geles, producidos durante el período de secado y como consecuenc:a de la mayor proximidad de estas partículas en este período.

Se ha observado también que si a la pasta de cemento se le ha permitido hidratarse durante un período largo, ésta queda menos afectada por estos enlaces adicionales durante el secado, de tal forma que al volver a colocarse en contacto con el agua un hormigón que, previamente a su desecación había sido sometido a un buen curado, éste apenas sí presenta retracción residual, siendo por tanto el proceso retracción-entumecimiento mucho más reversible que en hormigones sometidos a curados deficientes.

Se ha podido comprobar también que la pasta de cemento se vuelve insensible a los movimientos higrométricos cuando el secado del hormigón va acompañado de carbonatación, con lo cual la recuperación es más difícil y la retracción residual se incrementa o, lo que es igual, el entumecimiento es mucho menor.

En la figura 1 pueden verse representados los fenómenos indicados.

En el estudio de deformaciones debidas a variaciones higrométricas del hormigón de la presa a la que nos hemos referido en este trabajo no se pudo seguir la evolución completa del mismo, en la que se tuvieran en cuenta los efectos producidos por la desecación, debido a que cuando se extrajeron los testigos del hormigón, la presa llevaba construida varios años.

El control del entumecimiento sobre testigos de hormigón extraídos de la presa, se realizó sometiendo a éstos a una desecación previa hasta peso constante e introduciéndolos posteriormente en agua a temperatura controlada de $20^{\circ} \mathrm{C}$.

Sobre una base de $400 \mathrm{~mm}$ se midieron periódicamente los cambios dimensionales durante 140 días, por medio de un micrómetro que apreciaba la milésima de milímetro, y según se aprecia en la figura 2.

Los entumecimientos medidos crecían rápidamente al principio, para posteriormente y conforme avanzaba en tiempo de permanencia en agua, presentar un crecimiento más lerto (figura 3). 


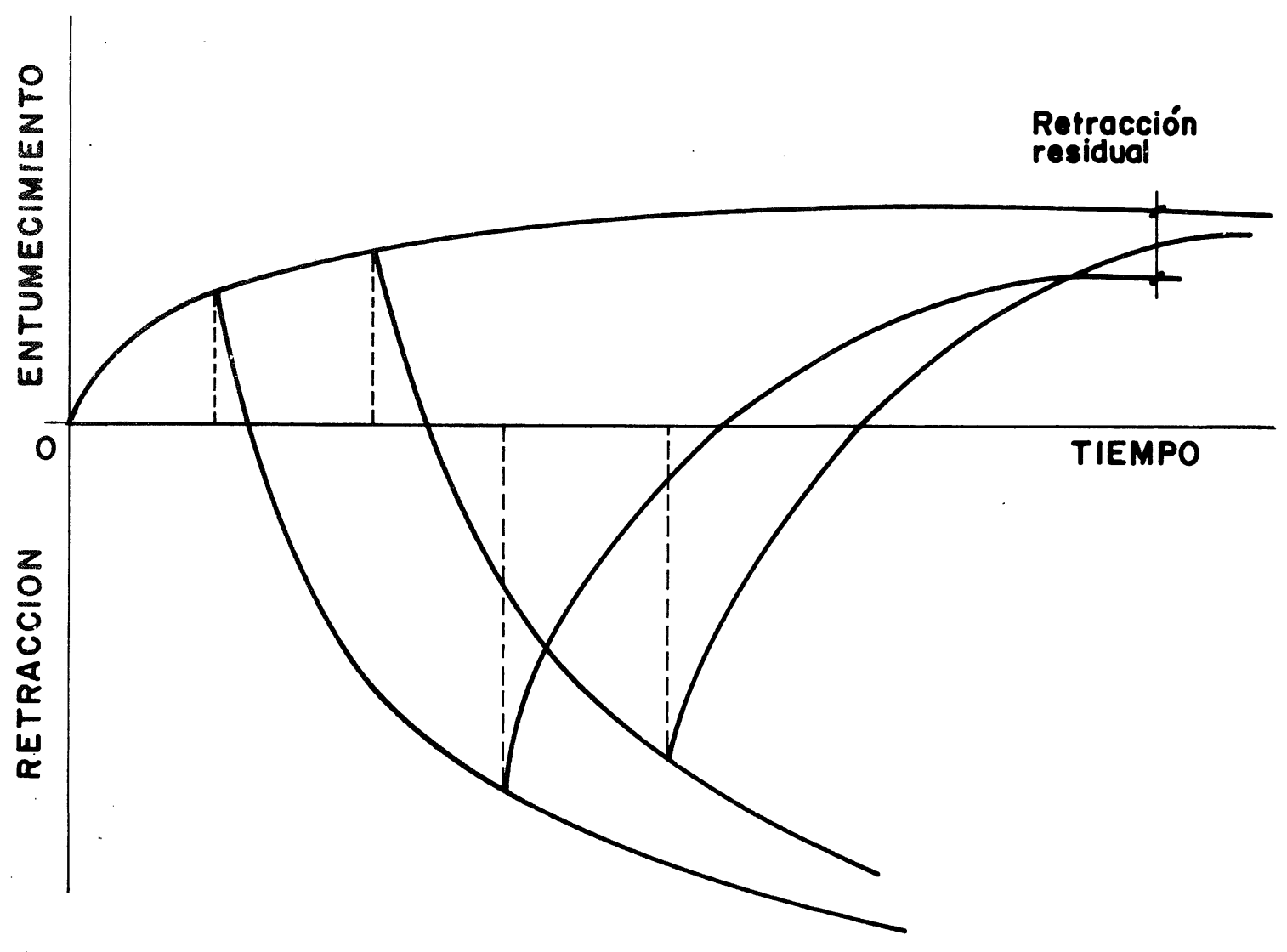

Fig. 1.

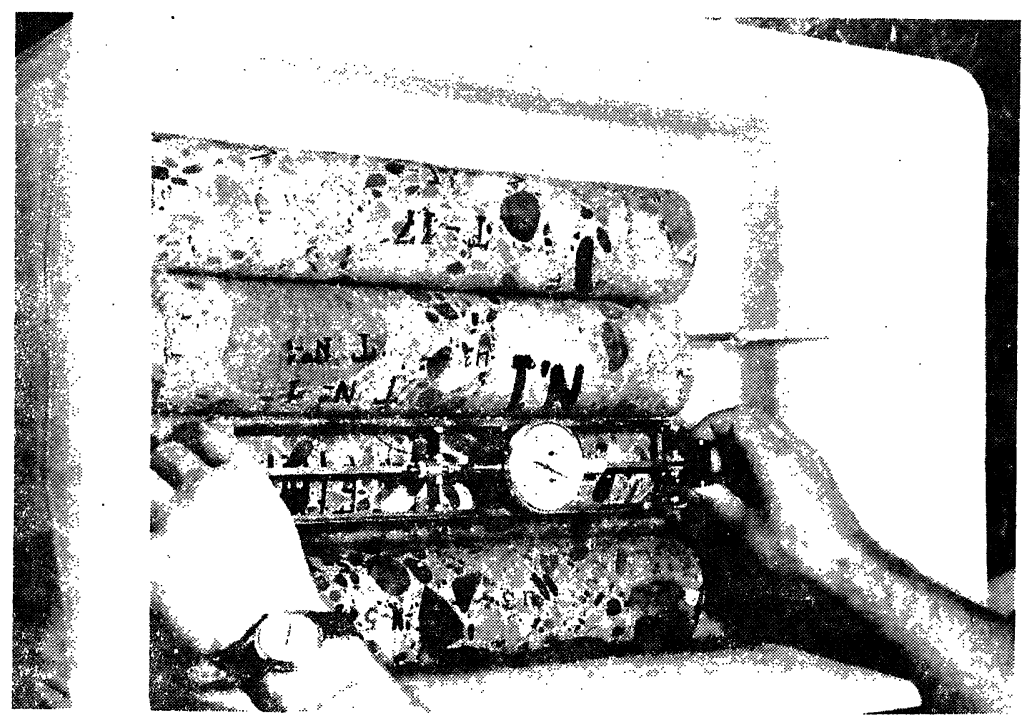

Fig. 2 


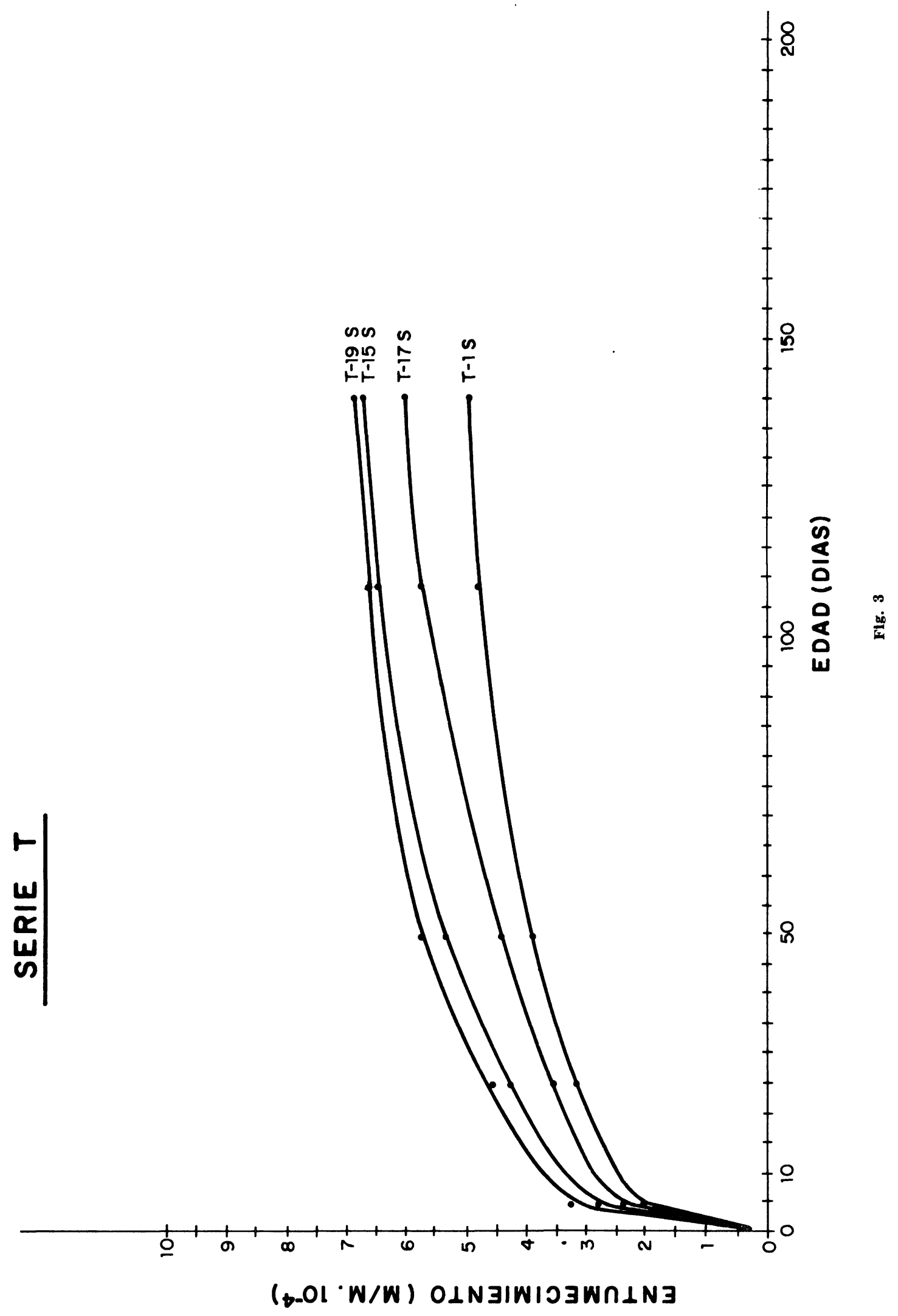


Dadas las variaciones presentadas y los valores obtenidos optamos por realizar un plan de ensayos en el que se tuviesen en cuenta diversas variables, a fin de observar cómo influían éstas en el entumecimiento. Las variables elegidas abarcaban fundamentalmente cementos y dosificaciones, dejando para una segunda fase otros aspectos también influyentes tales como tamaño máximo de árido, naturaleza del mismo, presencia de aditivos en el hormigón, etcétera.

En el estudio que se ha realizado las variables que se han manejado fueron: tres tipos de cemento, distintas dosificaciones de los mismos, diferentes relaciones agua/cemento y áridos/cemento, así como influencia de la desecación o no desecación previa al ensayo.

\section{PLAN DE ENSAYOS}

\subsection{Hormigones a estudiar}

Para el estudio de entumecimiento de hormigones, en contacto con agua, se confeccionaron varios tipos de hormigones empleando diferentes cementos frecuentes en el mercado nacional. Estos tipos y categorías de cemento fueron los siguientes:

Serie A. Cemento portland con adiciones activas PA-350.

Serie B. Cemento portland de alta resistencia inicial P-450 ARI.

Serie C. Cemento puzolánico PUZ-I-350.

Con cada uno de estos cementos se confeccionaron hormigones con diferentes dosificaciones de conglomerante, relaciones agua/cemento y relaciones árido/cemento.

Los valores de las distintas variables utilizadas en los hormigones ensayados son las que figuran en el siguiente cuadro:

\begin{tabular}{|c|c|c|c|c|}
\hline serie & Cemento & $\begin{array}{c}\text { Dosificación } \\
\text { cemento } \\
\left(\mathrm{kg} / \mathrm{m}^{3}\right)\end{array}$ & $\frac{\text { Agua }}{\text { Cemento }}$ & $\frac{\text { Aridos }}{\text { Cemento }}$ \\
\hline $\begin{array}{l}\text { A-1 } \\
\text { A-2 } \\
\text { A-3 } \\
\text { A-4 } \\
\text { A-5 } \\
\text { A-6 }\end{array}$ & PA-350 & $\begin{array}{l}350 \\
300 \\
250 \\
350 \\
300 \\
250\end{array}$ & $\begin{array}{l}0,55 \\
0,55 \\
0,55 \\
0,65 \\
0,65 \\
0,65\end{array}$ & $\begin{array}{l}4,98 \\
5,82 \\
6,98 \\
4,98 \\
5,82 \\
6,98\end{array}$ \\
\hline $\begin{array}{l}\text { B-1 } \\
\text { B-2 } \\
\text { B-3 } \\
\text { B-4 } \\
\text { B-5 } \\
\text { B-6 }\end{array}$ & P-450 ARI & $\begin{array}{l}350 \\
300 \\
250 \\
350 \\
300 \\
250\end{array}$ & $\begin{array}{l}0,55 \\
0,55 \\
0,55 \\
0,65 \\
0,65 \\
0,65\end{array}$ & $\begin{array}{l}4,98 \\
5,82 \\
6,98 \\
4,98 \\
5,82 \\
6,98\end{array}$ \\
\hline $\begin{array}{l}\text { C-1 } \\
\text { C-2 } \\
\text { C-3 } \\
\text { C-4 } \\
\text { C-5 } \\
\text { C-6 }\end{array}$ & PUZ-I-350 & $\begin{array}{l}350 \\
300 \\
250 \\
350 \\
300 \\
250\end{array}$ & $\begin{array}{l}0,55 \\
0,55 \\
0,55 \\
0,65 \\
0,65 \\
0,65\end{array}$ & $\begin{array}{l}4,98 \\
5,82 \\
6,98 \\
4,98 \\
5,82 \\
6,98\end{array}$ \\
\hline
\end{tabular}

La arena y la gravilla empleadas en los hormigones fueron de naturaleza silícea y esta última tenía un tamaño máximo de $20 \mathrm{~mm}$. 
En todos los hormigones se utilizó una composición única de los áridos, formada por 745 $\mathrm{kg}$ de arena y $1.000 \mathrm{~kg}$ de gravilla.

Los hormigones se mezclaron en una hormigonera basculante y se compactaron en mesa vibrante a 6.000 c.p.m.

Con cada uno de los hormigones, que componen cada Serie, se fabricaron cuatro probetas prismáticas de $10 \times 10 \times 43 \mathrm{~cm}$ para realizar los ensayos de entumecimiento y doce probetas cilíndricas de $15 \varnothing \times 30 \mathrm{~cm}$ para determinar su resistencia a compresión a 28 y 400 días. Las probetas cilíndricas se conservaron en cámara húmeda hasta el día anterior a su rotura.

Los valores de las resistencias medias a compresión a 28 y 400 días, así como la consistencia medida en cono de Abrams son los que figuran en el siguiente cuadro:

\begin{tabular}{|c|c|c|c|}
\hline \multirow{2}{*}{ Serle } & \multirow{2}{*}{$\begin{array}{l}\text { Asiento en cono de } \\
\text { Abrams }(\mathrm{cm})\end{array}$} & \multicolumn{2}{|c|}{$\begin{array}{l}\text { Resistencia a compresión } \\
\left(\mathrm{kp} / \mathrm{cm}^{2}\right)\end{array}$} \\
\hline & & 28 días & 400 días \\
\hline $\begin{array}{l}\text { A-1 } \\
\text { A-2 } \\
\text { A-3 } \\
\text { A-4 } \\
\text { A-5 } \\
\text { A-6 }\end{array}$ & $\begin{array}{r}4,6 \\
1,0 \\
0,0 \\
17,5 \\
4,8 \\
1,6\end{array}$ & $\begin{array}{c}288,5 \\
274,1 \\
267,0 \\
238,8 \\
196,3 \\
196,6\end{array}$ & $\begin{array}{l}370,2 \\
362,2 \\
345,8 \\
327,2 \\
281,1 \\
270,5\end{array}$ \\
\hline $\begin{array}{l}\text { B-1 } \\
\text { B-2 } \\
\text { B-3 } \\
\text { B-4 } \\
\text { B-5 } \\
\text { B-6 }\end{array}$ & $\begin{array}{r}3,9 \\
0,5 \\
0,0 \\
12,0 \\
3,2 \\
1,0\end{array}$ & $\begin{array}{l}336,5 \\
329,0 \\
324,7 \\
254,0 \\
250,6 \\
247,0\end{array}$ & $\begin{array}{l}428,3 \\
424,0 \\
425,2 \\
337,7 \\
325,5 \\
343,0\end{array}$ \\
\hline $\begin{array}{l}\text { C-1 } \\
\text { C-2 } \\
\text { C-3 } \\
\text { C-4 } \\
\text { C-5 } \\
\text { C-6 }\end{array}$ & $\begin{array}{r}6,5 \\
2,0 \\
0,5 \\
19,0 \\
5,2 \\
2,0\end{array}$ & $\begin{array}{l}250,2 \\
234,5 \\
224,3 \\
217,2 \\
205,0 \\
181,3\end{array}$ & $\begin{array}{c}332,7 \\
311,8 \\
318,0 \\
304,3 \\
270,6 \\
241,1\end{array}$ \\
\hline
\end{tabular}

\subsection{Técnica seguida}

Las probetas prismáticas a ensayar a entumecimiento se conservaron en cámara húmeda durante los primeros 28 días. A esta edad se extrajeron de la cámara dos probetas de cada Serie de hormigón que se desecaron en estufa a $100^{\circ} \mathrm{C}$ hasta conseguir la constancia de peso. Estas probetas constituyen las señaladas en los gráficos con la letra $\mathrm{S}$, después de la designación de la serie correspondiente.

Las otras dos probetas prismáticas de cada serie se llevaron directamente de la cámara húmeda a las balsas de agua para seguir la evolución de su variación dimensional en húmedo. Estas probetas constituyen las señaladas en los gráficos con la letra $H$ después de la designación de la serie correspondiente.

A las probetas desecadas en estufa, así como las procedentes de la cámara húmeda, se les colocaron índices de medida separados a $400 \mathrm{~mm}$, procediéndose a una primera lectura antes de introducirlas en las balsas; seguidamente y cada día se procedía a la lectura entre 
índices por medio de un micrómetro durante el primer mes, distanciando posteriormente las medidas por ser más pequeñas las variaciones.

Las balsas de agua se mantuvieron durante todo el tiempo que duró el ensayo a una temperatura de $20^{\circ} \mathrm{C}$.

\subsection{Resultados obtenidos}

El seguimiento de las variaciones de los diferentes hormigones sumergidos en agua se ha realizado durante 400 días.

Los resultados obtenidos se han llevado a gráficos en los que quedan representadas las curvas de entumecimiento en función del tiempo.

En las figuras 4,5 y 6 se representan las series A-S, B-S y C-S correspondientes a hormigones desecados a $100^{\circ} \mathrm{C}$ antes de introducirlos en agua, mientras que en las figuras 7, 8 y 9 se recogen las series A-H, B-H y $\mathrm{C}-\mathrm{H}$ correspondientes a hormigones que no habían sufrido ninguna desecación previa.

\section{CONCLUSIONES}

A la vista de los datos obtenidos en los ensayos realizados observamos lo siguiente:

1. Existe una gran diferencia entre los valores de entumecimiento obtenidos en hormigones desecados previamente a su colocación en contacto con agua y aquellos otros que no habían experimentado esta desecación previa y de la cámara húmeda habían sido trasladados al agua. La relación entre los valores obtenidos en uno y otro caso llega a ser de hasta 10.

2. A pesar de haber llegado con los ensayos hasta la edad de 400 días se observa que el aumento lineal no se estabiliza, aunque es decreciente siguiendo una ley logarítmica

3. La influencia del tipo de cemento empleado en el hormigón es notable, dándose el mayor entumecimiento para el cemento P-450 ARI, seguido del FUZ-I-350 y del PA-350. Este efecto se aprecia tanto en los hormigones desecados como en los que no lo fueron.

Se observa, por tanto, que los cementos de mayor finura de molido producen las mayores expansiones debido a su mayor poder de imbibición de agua.

4. La dosificación de cemento tiene una influencia también importante, obteniéndose los valores más elevados de entumecimiento para las dosificaciones más altas y decreciendo éstos con aquéllas.

Esta apreciación es lógica debido a que cuanto más alta sea la dosificación de cemento mayor será la cantidad de geles en el hormigón.

5." La relación agua/cemento influye apreciablemente en el sentido de que los hormigones en los que ésta es mayor presentan menor entumecimiento. 
Este hecho, que a primera vista puede parecer anormal, se explica si tenemos en cuenta que, al ser la relación agua/cemento menor, los poros son de menor diámetro y por tanto los efectos de absorción por capilaridad se hacen más efectivos.

6. En los hormigones ensayados se observan en general valores de entumecimiento superiores a los que dieron los testigos procedentes de la presa (serie T) a la misma edad de ensayo. Este hecho puede atribuirse a dos causas: en primer lugar a la diferencia de tamaños máximos de los áridos empleados; en el hormigón de la presa era frecuente encontrar áridos de $80 \mathrm{~mm}$, mientras que en los hormigones de los ensayos ei tamaño máximo era de $20 \mathrm{~mm}$, y en segundo lugar a que el hormigón de la presa tenía bastantes años y, por tanto, estaba sometido a un proceso de carbonatación mientras que el hormigón empleado en nuestros ensayos era un hormigón muy joven que tenía sólo 28 días cuando se iniciaron éstos.

7. $\quad$ El notable entumecimiento experimentado por hormigones que han sufrido un proceso de desecación de larga duración al aire, a temperaturas altas con la colaboración de humedades relativas bajas y que posteriormente se han puesto en contacto de forma permanente con agua - como ocurre en el caso de presas e incluso de depósitos de agua, en los que, por otra parte, es sólo uno de los paramentos el expuesto a la acción del agua, mientras que el otro permanece seco-, puede motivar efectos patológicos importantes que conviene tener en cuenta, especialmente cuando las superficies de estos paramentos son grandes. 


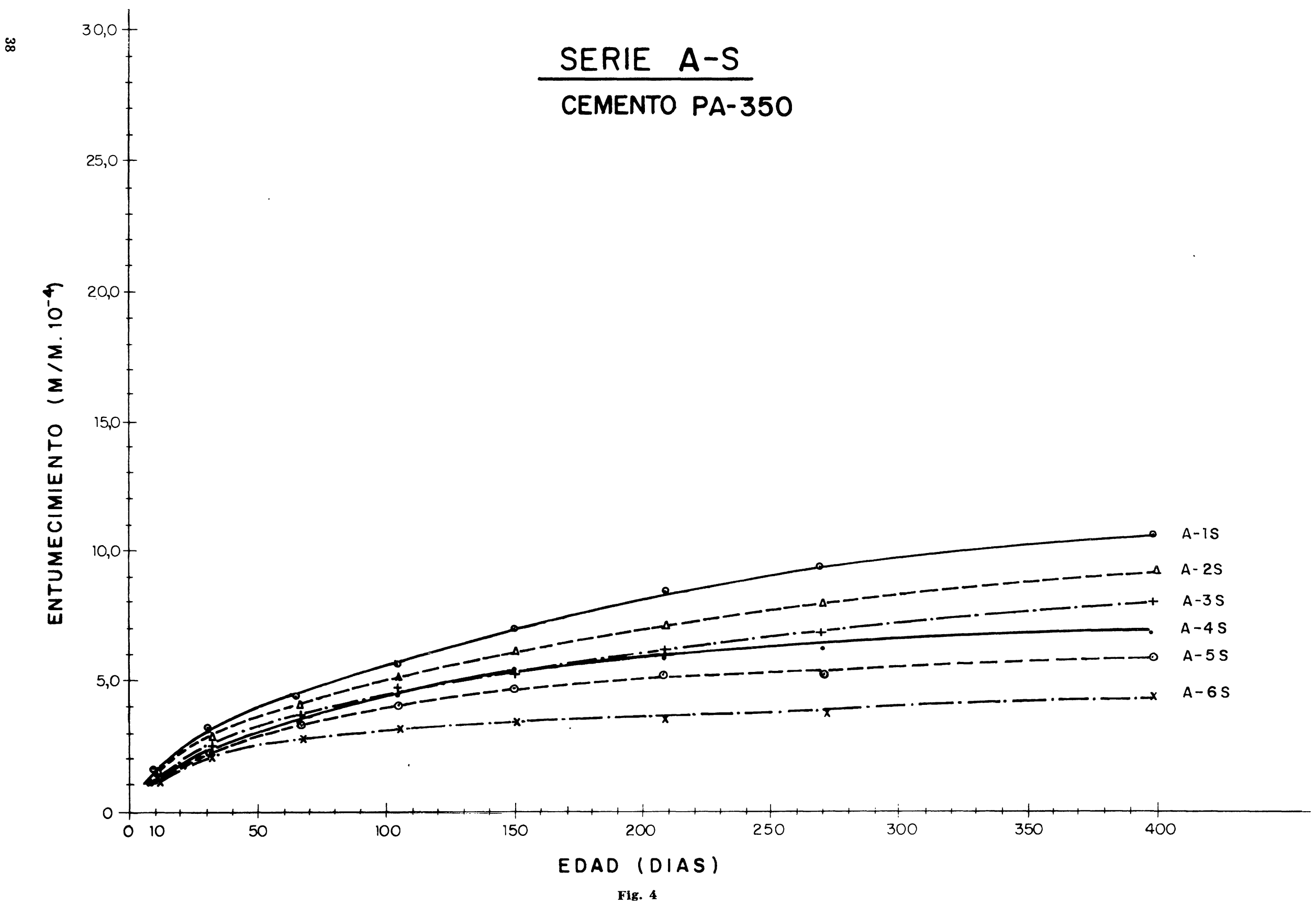

(c) Consejo Superior de Investigaciones Científicas Licencia Creative Commons 3.0 España (by-nc) 


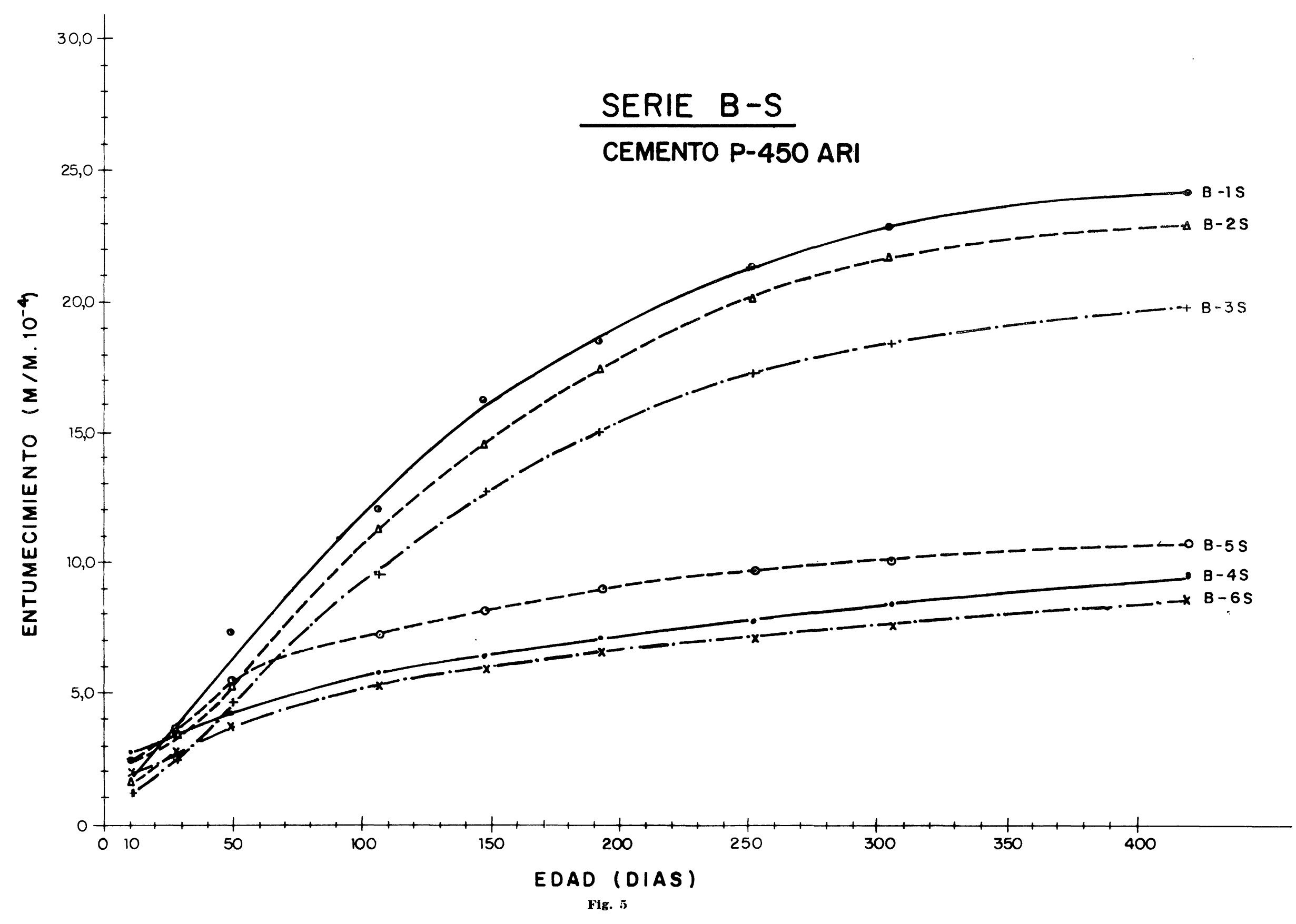




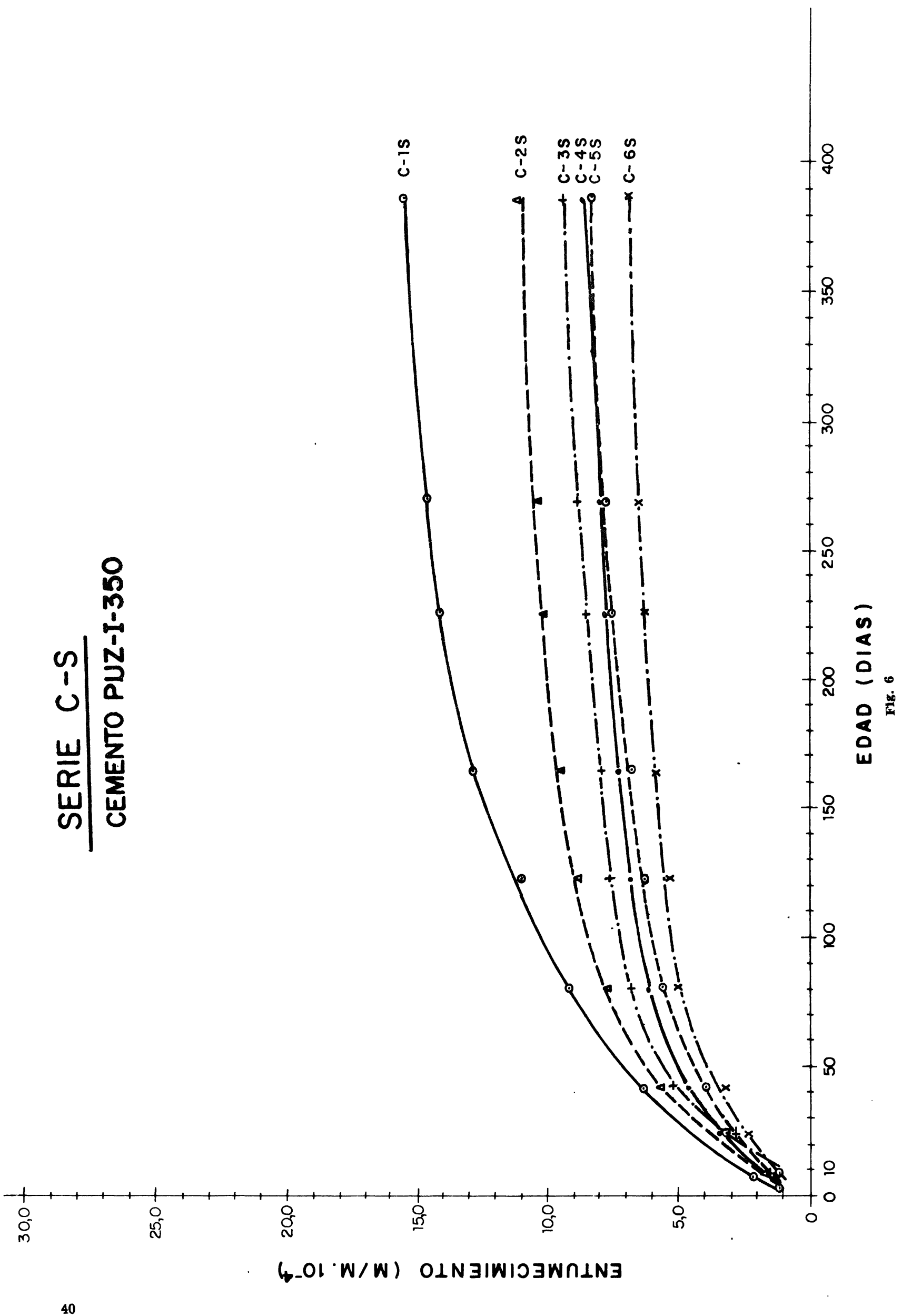




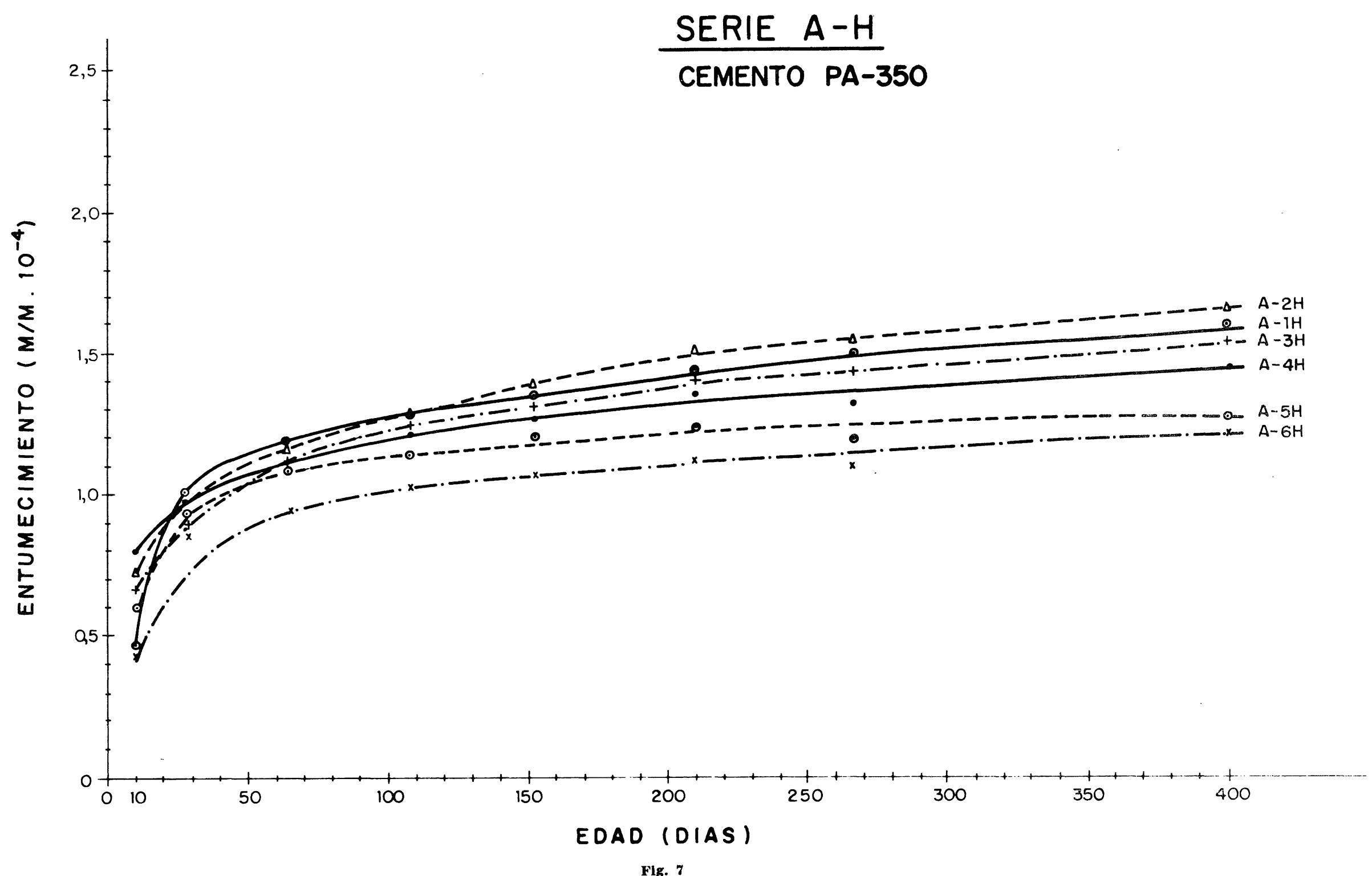




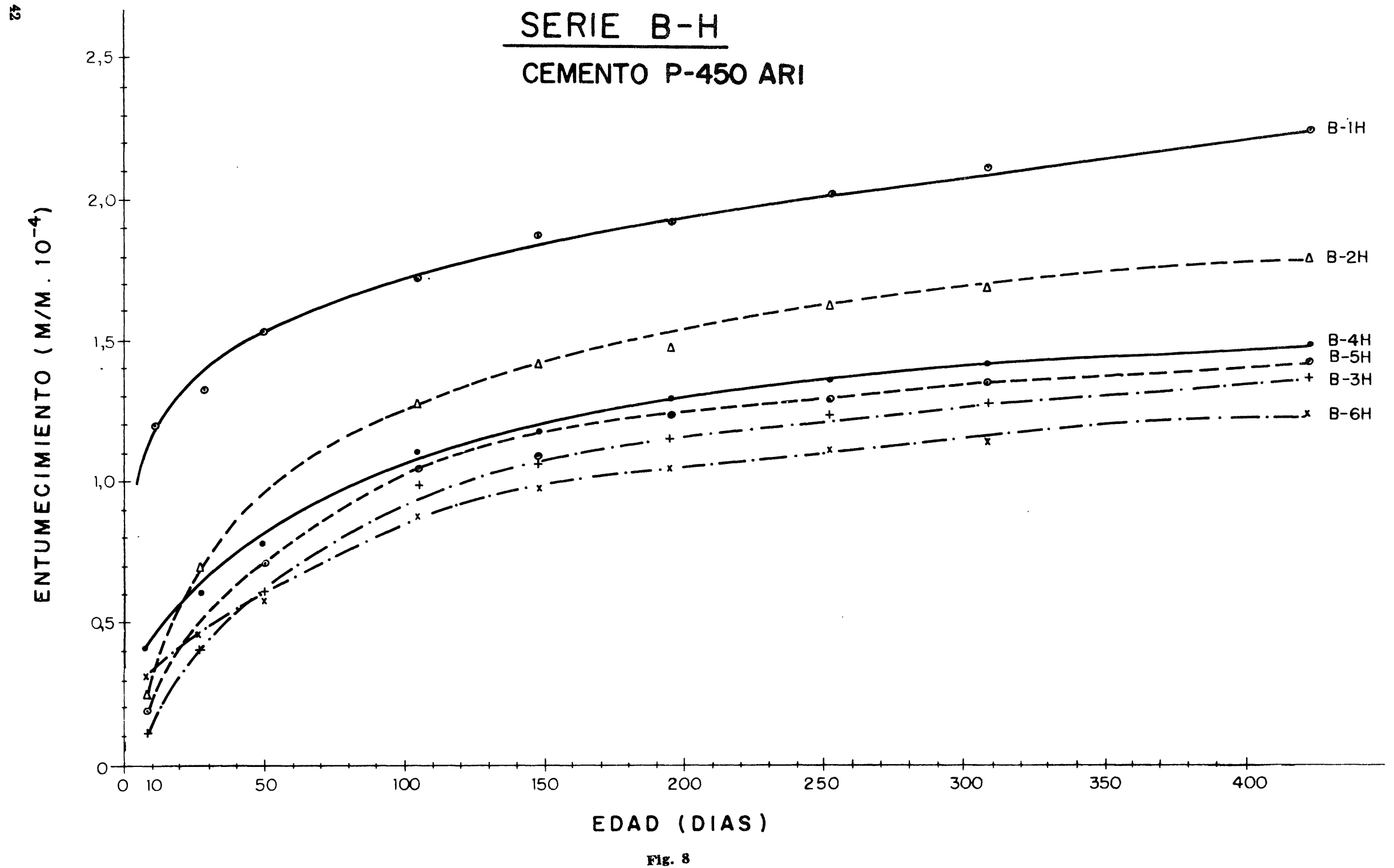




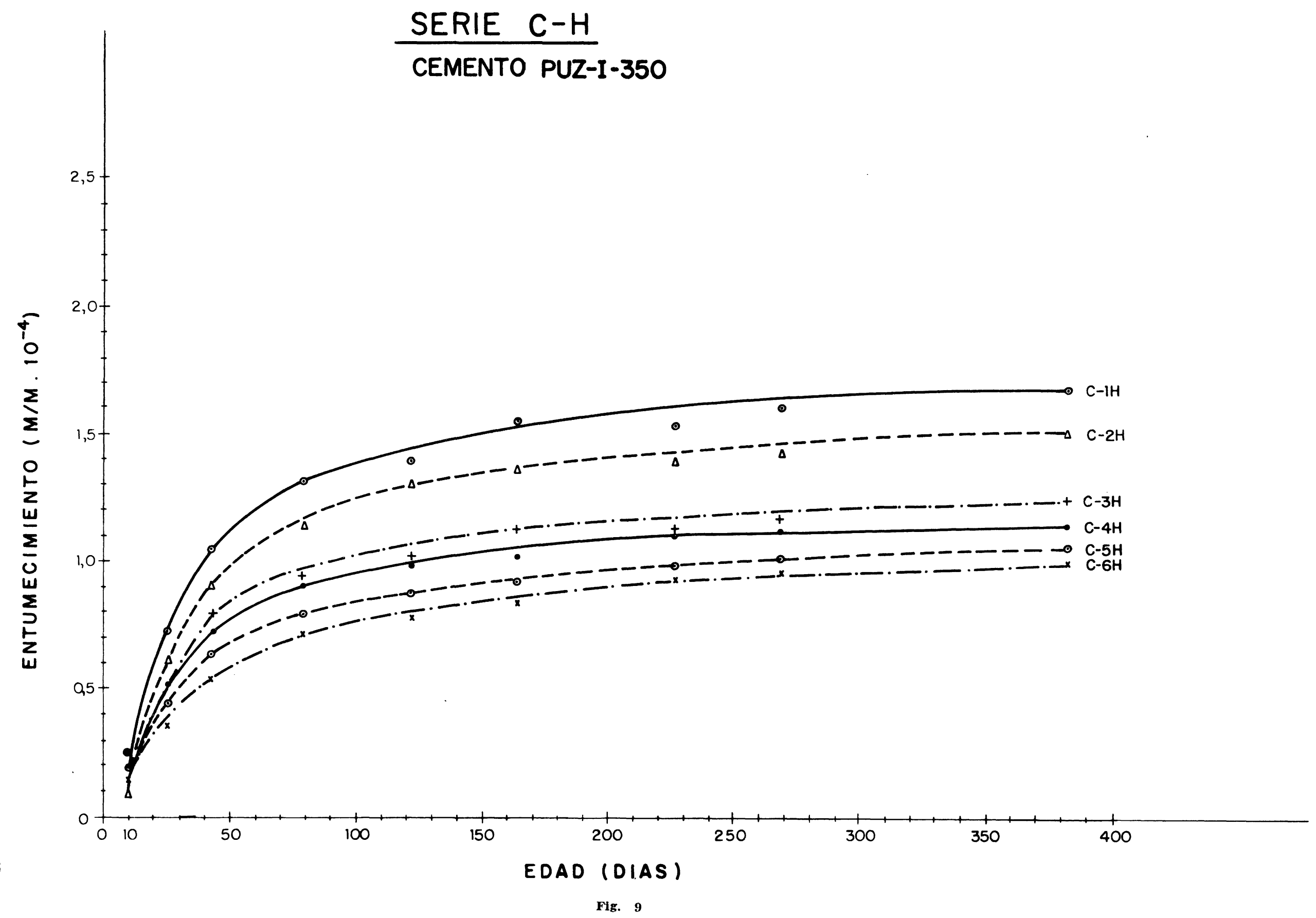

